\title{
GEOLOGIA DA FOLHA DE SANTA RITA DO PASSA QUATRO
}

\author{
Geólogo MARCOS MASSOLI
}

\begin{abstract}
This paper reports to the stratigraphic study of the Geological Superface Formation Mapping, in Santa Rita do Passa Quatro topographic sheet. This area is located between the $21^{\circ} 30^{\prime}$ and $21^{\circ} 45^{\prime}$ parallels and the $47^{\circ} 15^{\prime}$ and $47^{\circ} 30^{\prime}$ meridians, and is 700 square $\mathrm{km}$ width.

We describe in this area, at the eastern part of the Parana Basin, the following geological unities: Tatuí, Estrada Nova, Botucatu + Pirambóia and Serra Geral Formations. It is also found Tertiary and Quaternary sediments.
\end{abstract}

\section{RESUMO}

Os dados ora apresentados constituem a Estratigrafia do Projeto de Levantamento Geológico de Formações Superficiais, em andamento na folha de Santa Rita do Passa Quatro, situada entre os paralelos $21^{\circ} 30^{\prime}$ e $21^{\circ} 45^{\prime}$ e os meridianos $47^{\circ}$ $15^{\prime}$ e $47^{\circ} 30^{\prime}$, com uma área de aproximadamente $700 \mathrm{~km}$.

$\mathrm{Na}$ área em questão, situada na borda oriental da Bacia do Paraná, foram mapeadas e descritas as seguintes unidades geológicas: Formação Tatuí; Formação Estrada Nova; Formação Botucatu + Pirambóia; Formação Serra Geral; Formações Terciárias e Quaternárias.

\section{INTRODUÇÃO}

Este trabalho é uma parte do Projeto de Levantamento Geológico de Formações Superficiais, iniciado pelo Instituto Geológico em 1976. Como área piloto foi escolhida a folha de Leme, por se acharem nela representadas nove unidades geológicas diferentes: Grupo Tubarão Indiviso; Formação Irati; Formação Estrada Nova; Formação Pirambóia; Formação Botucatu; Formação Serra Geral; Intrusivas Básicas; Formações Terciárias e Quaternárias.

Objetivo: A finalidade deste levantamento é dar continuidade ao projeto acima, com a elaboração do mapa geclógico da quadrícula, a verificação do comportamento estrutural das formações geológicas, bem como a caracterização das diferentes unidades estratigráficas. Em seguida, serão obtidos os dados referentes às formações superficiais, de grande utilidade à Engenharia, Agronomia, Pedologia e à própria Geologia.

Localização: A folha, editada pelo Instituto Brasileiro de Geografia, no ano de 1971, na escala de 1:50.000, situa-se na região nordeste do Estado de São Paulo, entre os paralelos $21 .^{\circ} 30^{\prime}$ e $21 .^{\circ} 45^{\prime}$ e os meridianos $47 .^{\circ} 15^{\prime}$ e $47 .^{\circ} 30^{\prime}$, possuindo uma superfície de, aproximadamente, 700 $\mathrm{km}^{2}$.

Estudos Prévios: Alguns trabalhos foram realizados na área, mas sem a abrangência e a pormenorização deste. Destacam-se: alguns comentários geológicos e feições geomorfológicas (Bol. 41 - IGG); mapeamento geológico na escala de 1:100.000, por MEZZALIRA (1965), da folha de Casa Branca; mapeamento da região nordeste do Estado, por SOARES et alii (1973), cuja 
parte sul limita-se com o extremo norte da folha de Santa Rita do Passa Quatro e, finalmente, os trabalhos do Projeto Sapucaí, da CPRM (1977), na escala de 1:250.000, que alcançam a área em estudo.

A carência de folhas geológicas do Estado, na escala de 1:50.000, sentida pela comunidade geológica, justifica plenamente a elaboração desses mapas, contribuindo para ampliar o conhecimento e a distribuição das unidades litológicas no Estado de São Paulo.

Metodologia: Os trabalhos foram realizados mediante uma combinação de fotointerpretação com o mapeamento de campo. A área em questão é totalmente recoberta por fotos aéreas, de 1971, na escala aproximada de 1:25.000.

Inicialmente foi feito um reconhecimento preliminar de campo, cujos dados obtidos forneceram subsídios para os trabalhos de fotointerpretação, realizados na sede. Posteriormente executou-se o levantamento de campo, através do caminhamento ao longo de estradas, leitos de córregos, etc., sendo que os pontos estudados foram descritos em caderneta de campo e anotados no mapa base. Paralelamente procedia-se à coleta de amostras para ensaios granulométricos.

O material utilizado constituiu-se de bússola, altímetro, lupa, ímã e martelo, além da folha base.

\section{ASPECTOS GEOGRÁFICOS}

Relevo: A área levantada apresenta duas características fisiográficas distintas, compondo as unidades geomorfológicas das "Cuestas Basálticas" e a da "Depressão Periférica".

As "Cuestas Basálticas", que ocupam grande parte da área, compreendem, litologicamente, as rochas mesozóicas da Bacia do Paraná, representadas pelas Formações Botucatu + Pirambóia e Serra Geral. Constituem elevações assimétricas, com escarpas abruptas em um lado (frente de cuesta) e caimento suave no outro, também chamado reverso de cuesta.

É nesta unidade que se encontra o ponto culminante da área, com altitude de 1.000 metros, localizado na Serra do Córrego Fundo.
A "Depressão Periférica" é composta por rochas do Paleozóico, representadas pelas Formações Estrada Nova e Tatuí. Aparece a SW, NE e E-SE da quadrícula. Caracteriza-se por uma topografia suave, cujas altitudes máxima e mínima estão em torno de 740 e 530 metros, respectivamente. Essa unidade geomorfológica, cuja origem é discutível - se erosiva ou estrutural - acha-se rebaixada entre o Complexo Cristalino, a E, e as "Cuestas Basálticas", a W.

Hidrografia: A folha de Santa Rita do Passa Quatro é drenada pelas bacias hidrográficas dos rios Pardo e Mogi Guaçu, sendo este o principal afluente daquele e localizado em sua margem esquerda.

Clima: As características são bem definidas no inverno e verão, quando apresentam, respectivamente, tempo seco e chuvoso. A temperatura anual média é de $20,6^{\circ}$, com máxima de $27,7^{\circ}$ e mínima de $15,3^{\circ}$; a precipitação anual está em torno de $1.940 \mathrm{~mm}$, enquanto a evaporação anual é de, aproximadamente, $1.852 \mathrm{~mm}$ (DAEE: 1972).

Aspectos da Vegetação: A predominância do clima tropical úmido e a baixa qualidade do solo, propiciaram o desenvolvimento dos cerrados em grande parte da área, notadamente da porção central para $\mathrm{N}$ e NW. São os cerrados constituídos por arbustos e árvores de pequeno porte, caracterizados pela tortuosidade de seus troncos. Gramíneas e ervas completam o revestimento do solo, essencialmente arenoso.

Muitas áreas de cerrados estão, atualmente, sendo reflorestadas por eucaliptos e pinus. E necessário salientar que parte da vegetação deu lugar à ocupação agropecuária.

\section{LITOESTRATIGRAFIA}

$\mathrm{Na}$ área, situada na borda oriental da Bacia do Paraná, a aproximadamente 25 $\mathrm{km}$ do Embasamento Cristalino, ocorrem rochas de idades compreendidas entre 0 Neo-Paleozóico (F. Tatuí) e o Quaternário (Aluvião), com exceção das Formações Irati e Bauru que não são aí registradas, ou por terem sido removidas pela erosão, ou mesmo por não terem sido depositadas na região. Em termos de área aflorante, há predominância das rochas do Mesozóico. 
O Permiano está representado pelas Formações Tatuí e Estrada Nova, separadas por uma discordância erosiva.

O Cretáceo está representado pelas Formações Botucatu + Pirambóia e Serra Geral.

O Cenozóico também se faz presente na área, sendo representado por sedimentos Terciários e Quaternários.

Em linhas gerais, as formações ocorrentes apresentam, estratigraficamente de baixo para cima, as seguintes características:

Formação Tatuí: Constituída por siltitos arenosos, de cor avermelhada, predominantemente maciços, podendo apresentar incipiente acamamento plano-paralelo. Subjacentes aos siltitos ocorrem, localmente, arenitos finos, esbranquiçados, com poucos metros de espessura, exibindo estratificação cruzada de pequeno porte. A parte basal da formação não ocorre na área. Entretanto, a $\mathrm{N}$ da mesma, na rodovia Cajuru-Mococa, esse contato com a formação subjacente se dá através de uma discordância erosiva, segundo SOARES et alii (1973).

Sua faixa aflorante restringe-se a NE da folha, nas proximidades do Ribeirão Quebra-Cuia. SOARES et alii (1973) estimam para a Formação Tatuí, na rodovia CajuruMococa, uma espessura de cerca de 30 metros.

A origem da Formação Tatuí relacionase com uma transgressão marinha que se deu logo após o término do ciclo glacial (CPRM, 1977). Sua litologia sugere um ambiente oxidante, de águas rasas e calmas. Segundo SOARES et alii (1973), a origem do Tatuí é muito duvidosa, devendo estar associada a planícies costeiras do início do ciclo pós-glacial.

Formação Estrada Nova: Sua faixa de exposição localiza-se a SW, NE e E-SE da folha. Está representada por siltitos arenosos e argilosos, predominantemente arroxeados, com acamamento plano-paralelo e, freqüentemente, fraturamento concoidal. $\mathrm{Na}$ parte superior da formação, comumente, encontram-se camadas apresentando fragmentos de sílex de cor escura. A NE da quadrícula, ocorrem blocos de sílex, assemelhando-se a matacões de diabásio, em meio aos siltitos arenosos e arroxeados. Acreditava-se, a princípio, que esse sílex fosse originado a partir de soluções residuais do vulcanismo basáltico que se manifestou na Bacia do Paraná durante o Mesozóico. Porém, o fato de existirem arenitos silicificados posteriores ao vulcanismo básico, deu margem a outras origens: (AMARAL, 1961; 1971; WERNICK, 1966).

A SW da área encontram-se camadas centimétricas de siltitos calcíferos intercalados aos siltitos arenosos, diferenciando-se destes pela coloração mais clara e maior tenacidade. Próximo a esse local foi assinalada uma camada fossilífera, de aproximadamente $15 \mathrm{~cm}$ de espessura, contendo restos de peixes indeterminados. Esse afloramento, com altitude de $560 \mathrm{~m}$, localiza-se próximo ao topo do Estrada Nova, estando a, aproximadamente, $500 \mathrm{~m}$ do contato com o Mesozóico, contato esse verificado por falhamento que elevou os sedimentos paleozóicos.

A cerca de $1 \mathrm{~km}$ da estação ferroviária de Tambaú, no sentido para São Simão, num corte da estrada de ferro, ocorrem, também, restos de peixes, estando o afloramento a $680 \mathrm{~m}$ de altitude e próximo ao topo da formação. MEZZALIRA (1966) cita a existência de um jazigo, contendo restos vegetais, localizado próximo a essa estação. No extremo SE da folha, MEZZALIRA (op. cit.), assinala a ocorrência de lamelibrânquios em siltitos arenosos esverdeados.

A $4 \mathrm{~km}$ a SE de Santa Rosa do Viterbo e a $1 \mathrm{~km}$ além do limite $\mathrm{N}$ da área, há uma pedreira, em atividade, explorando calcário dolomítico, o qual ocorre em camada de quase $2 \mathrm{~m}$ de espessura, encaixada em siltitos arroxeados atribuídos à Formação Estrada Nova. Esse calcário contém fragmentos de ossos de répteis pertencentes, possivelmente, a Mesosaurus sp, fóssil considerado exclusivo da Formação Iratí, até então não encontrada aflorando nessa área que, por isso deverá merecer estudos mais detalhados, tanto estratigráficos como paleontológicos, visando o esclarecimento do problema acima exposto.

O contato superior do Estrada Nova se faz através de uma discordância erosiva, acompanhada por uma camada de sílex, tal como pode ser visto na ferrovia que liga Tambaú a São Simão, na altura do km 200.

A base do Estrada Nova acha-se em discordância erosiva com o Tatuí. Esse contato, fora da folha, situa-se na estrada que vai de Santa Rosa do Viterbo para 
São Pedro dos Morrinhos. Segundo SOARES E LANDIN (1973), esse contato está representado por conglomerado e breccia, com até $3 \mathrm{~m}$ de espessura, com seixos predominantemente de sílex, sotopostos a arenitos finos, de cores claras, interacamados com siltitos laminados do Estrada Nova. Abaixo do conglomerado estão os siltitos avermelhados da Formação Tatuí.

Baseado nesse contato inferior, pode-se estipular uma espessura de cerca de $70 \mathrm{~m}$ para o Estrada Nova, na parte NE da área. Nas proximidades de Tambaú, essa espessura não pode ser estimada, devido à existência de uma extensa saleira ("sill") de diabásio posicionado entre o Estrada Nova e o Tubarão.

Admite-se que a origem da Formação Estrada Nova esteja relacionada à sedimentação, em planícies de marés, de uma bacia intracontinental de águas rasas e salobras (VIEIRA, 1973). O fato de terem sido encontrados restos fósseis de peixes e de vegetais muito próximos entre si (em Tambaú) reforça essa teoria.

Formação Botucatu + Pirambóia: É a formação mais representativa da área em estudo, tendo bastante expressão tanto na horizontal como na vertical.

Esta formação representa a fase inicial da sedimentação mesozóica. E caracterizada por arenitos de cores rosadas, esbranquiçadas e, mais raramente, esverdeadas. Granulometricamente predomina a fração areia fina, na qual o diâmetro das partículas varia entre 0,250 e $0,125 \mathrm{~mm}$. Os grãos, predominantemente de quartzo, são angulosos a arredondados e o grau de seleção da amostra total situa-se entre o moderadamente selecionado e o muito pobremente selecionado. $\mathrm{O}$ teor em argila varia entre $3 \%$ e $21 \%$ sendo, em média, de $9 \%$ (em 22 amostras).

As estruturas sedimentares mais comuns são a estratificação cruzada e o acamamento plano-paralelo. Elas podem ser vistas no corte da ferrovia que liga Tambaú a São Simão, na altura do km. 201, onde também estão presentes estruturas de escavação e preenchimento de canais. $\mathrm{Na}$ parte SE da folha, ao lado da rodovia Santa Cruz das Palmeiras-Tambaú, podem ser encontrados pequenos prismas de arenito, formados por diaclasamentos verticais oriundos das atividades ígneas. Junto ao contato com a rocha básica, o arenito apresenta-se esveŕdeado.

Devido à sua constituição litológica, esta formação encontra-se bastante alterada pelos processos intempéricos, razão por que acha-se recoberta por extensos areiais que podem ser confundidos com os sedimentos cenozóicos. Os melhores afloramentos ocorrem nas escarpas das serras e nos cortes da nova ferrovia.

É comum a ocorrência de intrusões de diabásio, podendo ser citadas as serras de São Pedro e Santa Vitória, a NE da folha, onde uma soleira de diabásio, com até 120 $\mathrm{m}$. de espessura, introduziu-se próximo à base da formação. Pequenas soleiras dentro do arenito podem ser observadas próximo ao povoado de Nhumirim, onde o corte da rodovia mostra, também, o capeamento terciário sobrejacente à linha de seixos. Outras soleiras de pequenas dimensões são comuns ao longo de cursos d'água, provocando o aparecimento de cachoeiras de alguns metros de altura. Diques estreitos e alongados ocorrem a E de Santa Rita do Passa Quatro, sobressaindo na topografia em forma de cristas resistentes à erosão; eles são relacionados a zonas de falhas.

A espessura máxima da formação gira em torno de 200 metros (a NW da Serra do Córrego Fundo) e a mínima é de cerca de 50 metros (a S de Santa Rita do Passa Quatro).

Geneticamente os sedimentos desta unidade podem ser divididos em 3 fácies: de canal, torrencial e eólica. A $1 .^{\mathrm{a}}$ é caracterizada por depósitos de rios meandrantes, constituídos por arenitos pouco selecionados exibindo estratificação cruzada e acamamento plano-paralelo. A fácies torrencial compreende arenitos conglomeráticos contendo seixos cujo diâmetro maior alcança até 5 centímetros de comprimento; é característica de depósitos de rios temporários de borda de deserto, originando planícies pedregosas. A fácies eólica, com arenitos bem selecionados exibindo estratificação cruzada, evidencia um ciclo desértico, com a sedimentação de areias transportadas pelo vento (SOARES e LANDIM, 1973).

Formação Serra Geral: Foram considerados como pertencentes a esta formação os magmatitos básicos, bem como o solo 
proveniente de sua decomposição, denominado "terra roxa".

As rochas desta unidade ocorrem a $\mathrm{S}$ e SE de Santa Rita do Passa Quatro e nas Serras de São Simão, Santo Onofre, Córrego Fundo, Sertãozinho, São Pedro e Santa Vitória.

Macroscopicamente são rochas de cor verde-escuro a preta, textura fanerítica, estrutura maciça e granulação média a fina. Normalmente as rochas encontram-se alteradas, constituindo a "terra roxa", de excelente qualidade para o aproveitamento agrícola.

Uma estrutura ocorrente nesta formação é a de disjunção colunar, que dá origem a grandes prismas hexagonais de diabásio, comuns na Serra do Córrego Fundo, onde há pedreiras em atividades. Esses prismas são formados por juntas de contração originadas com o decréscimo de volume do magma, por ocasião de seu resfriamento.

Os magmatitos básicos originaram-se a partir de intenso diastrofismo de ruptura (tafrogênese), acompanhado de vulcanismo básico que ocorreu, na Bacia do Paraná, desde o fim do Jurássico até o Cretáceo.

Segundo AMARAL et alii (1966), esse vulcanismo básico tem uma idade que varia de 90 a 150 milhões de anos.

A maior espessura desta formação é encontrada na Serra de Santa Vitória, proximidades da fazenda do mesmo nome, medindo cerca de $130 \mathrm{~m}$.

Sedimentos Cenozóicos: São de ocorrência ampla, apresentando grande extensão, mas pouca espessura.

Os sedimentos terciários constituem-se de depósitos arenosos com, no máximo, $10 \mathrm{~m}$. de espessura, capeando antiga superfície de erosão. $\mathrm{Na}$ base apresentam linhas de seixos ou cascalheiras, representadas por seixos de quartzo e por fragmentos de limonita.

Os quaternários, compostos por areias e argilas originadas dos sedimentos terciários e do Estrada Nova, respectivamente, ocorrem como depósitos aluviais associados aos principais rios, como o Rio Claro, Ribeirão Quebra-Cuia, etc.

\section{GEOLOGIA ESTRUTURAL}

A área em estudo localiza-se próximo à borda oriental da Bacia do Paraná, em uma fossa tectônica com a forma elipsoidal, de eixo maior com direção NNE-SSW (representado pelo Rio Paraná) e que se acha encravada no escudo Pré-Cambriano em Minas Gerais, São Paulo, Mato Grosso, Paraná, Santa Catarina, Rio Grande do Sul, Paraguai, Uruguai e Argentina, abrangendo uma área com cerca de $1.600 .000 \mathrm{~km}^{2}$.

As feições estruturais da região são representadas por falhas verticais, originadas a partir de movimentos epirogenéticos causados pelas intrusões ₹ extrusões de rochas básicas que, sobrecarregando a crosta, causaram uma subsidência da mesma, provocando o aparecimento de forças verticais. Como conseqüência, esses falhamentos, atingindo grandes profundidades, propiciaram a subida do magma básico que, ocupando espaços abertos, vieram a constituir os diques, cujas ramificações permitiram as intrusões de diabásio, dando origem às espessas e extensas soleiras, muito comuns na área.

Uma falha preenchida por diabásio ocorre a E de Santa Rita do Passa Quatro, no Morro do Itatiaia. E caracterizada por um alongamento saliente na topografia, com direção aproximada $\mathrm{N} 10 .{ }^{\circ} \mathrm{E}$. O flanco leste foi levantado, colocando o arenito conglomerático do Mesozóico a uma altitude de $900 \mathrm{~m}$., estimando-se um rejeito de $100 \mathrm{~m}$.

A análise estrutural da folha, baseada na rede de drenagem (tendo sido tomados elementos de drenagem de comprimentos iguais e maiores que $1 \mathrm{~km}$.), revelou uma direção preferencial N5. ${ }^{\circ} \mathrm{E}$, e direção secundária $\mathrm{N} 45 .^{\circ} \mathrm{W}$.

As camadas sedimentares constituem a estrutura denominada monoclinal, na qual as diferentes unidades geológicas mergulham no mesmo sentido, com o mesmo valor angular. Nessa área os mergulhos são dirigidos para NW, tendo um ângulo de, aproximadamente, $\frac{1 .^{\circ}}{2}$. Localmente os pacotes sedimentares podem apresentar mergulhos maiores, devido a arqueamentos provocados por intrusões de diabásio que, por sua vez, estão relacionadas a falhamentos. 


\section{CONSIDERAÇÕES ECONÔMICAS}

Os recursos econômicos existentes compreendem as argilas, areias e as rochas básicas inalteradas.

As argilas, fornecidas pela Formação Estrada Nova, são exploradas nas proximidades de Tambaú, cidade de tradição cerâmica. Elas são destinadas ao fabrico de tijolos, telhas, manilhas, além de objetos de uso doméstico, tais como: vasos, moringas, potes, etc. O material escavado das jazidas é transportado para as olarias, onde é trabalhado manual ou mecanicamente, dependendo do fim a que se destina.

As areias, utilizadas para o fabrico de vidro, ocorrem sob a forma de aluviões, cujo material foi retrabalhado a partir dos depósitos terciários. Atualmente estão sendo exploradas nas cabeceiras do Ribeirão Quebra-Cuia e do Córrego do Faveiro.

De grande importância econômica são os diabásios, que são destinados à pavimentação de ruas, calçadas e rodovias. A Serra do Córrego Fundo está sendo explorada comercialmente. Os diabásios parcialmente alterados são utilizados na conservação de estradas não asfaltadas.

Os arenitos silicificados podem ser empregados na construção de calçadas, guias de sarjetas e, também, como ornamento, no revestimento externo de paredes de residências.

A água subterrânea é um recurso praticamente inexplorado, pois não existem poços profundos na área, uma vez que as cidades de Santa Rita do Passa Quatro e Tambaú são abastecidas por água superficial; o que ocorrem são poços rasos, para uso exclusivamente doméstico. Porém, com a crescente poluição dos mananciais superficiais, num futuro não muito distante, as cidades, forçosamente, terão que recorrer à água subterrânea para seu suprimento. No caso de Santa Rita do Passa Quatro, o aquífero a ser explorado será o conjunto Botucatu + Pirambóia, com intercalação de magmatito básico. Tambaú, estando assentada sobre o Estrada Nova (de importância hidrogeológica insignificante), deverá explorar o aquífero subjacente, representado pelo Grupo Tubarão.

\section{CONCLUSOOES}

Os dados obtidos nos permitem algumas conclusões preliminares:

1. Fisiograficamente predomina a unidade geomorfológica das "Cuestas Basálticas", formando serras com escarpas abruptas e reverso suave.

2. A "Depressão Periférica" ocorre nas porções SW, NE e E-SE da área, mostrando uma topografia suave e abatida em relação ao Embasamento Cristalino, a E, e às "Cuestas Basálticas", a W.

3. A formação Botucatu + Pirambóia está representada pelas fácies de canal, eólica e torrencial.

4. Os sedimentos cenozóicos são de ocorrência ampla, apresentando muita expressão em superfície e pouca em profundidade. Limitam-se a extensos capeamentos de espigão, de pouca espessura, e às planícies de inundação dos rios principais.

5. Os falhamentos são verticais, estando seus respectivos planos, geralmente, preenchidos por diabásio. As direções mais significativas de lineamentos são $\mathrm{N} 5{ }^{\circ} \mathrm{E}$ e N45. ${ }^{\circ} \mathrm{W}$.

6. O mergulho das camadas, de estrutura monoclinal, é dirigido para NW, tendo um valor de cerca de $\frac{1 .^{\circ}}{2}$.

\section{AGRADECIMENTOS}

O autor agradece ao Prof. Dr. Ruy Osório de Freitas, pela orientação dada nos trabalhos de campo e ao Dr. Sérgio Mezzalira, pela revisão do texto. 

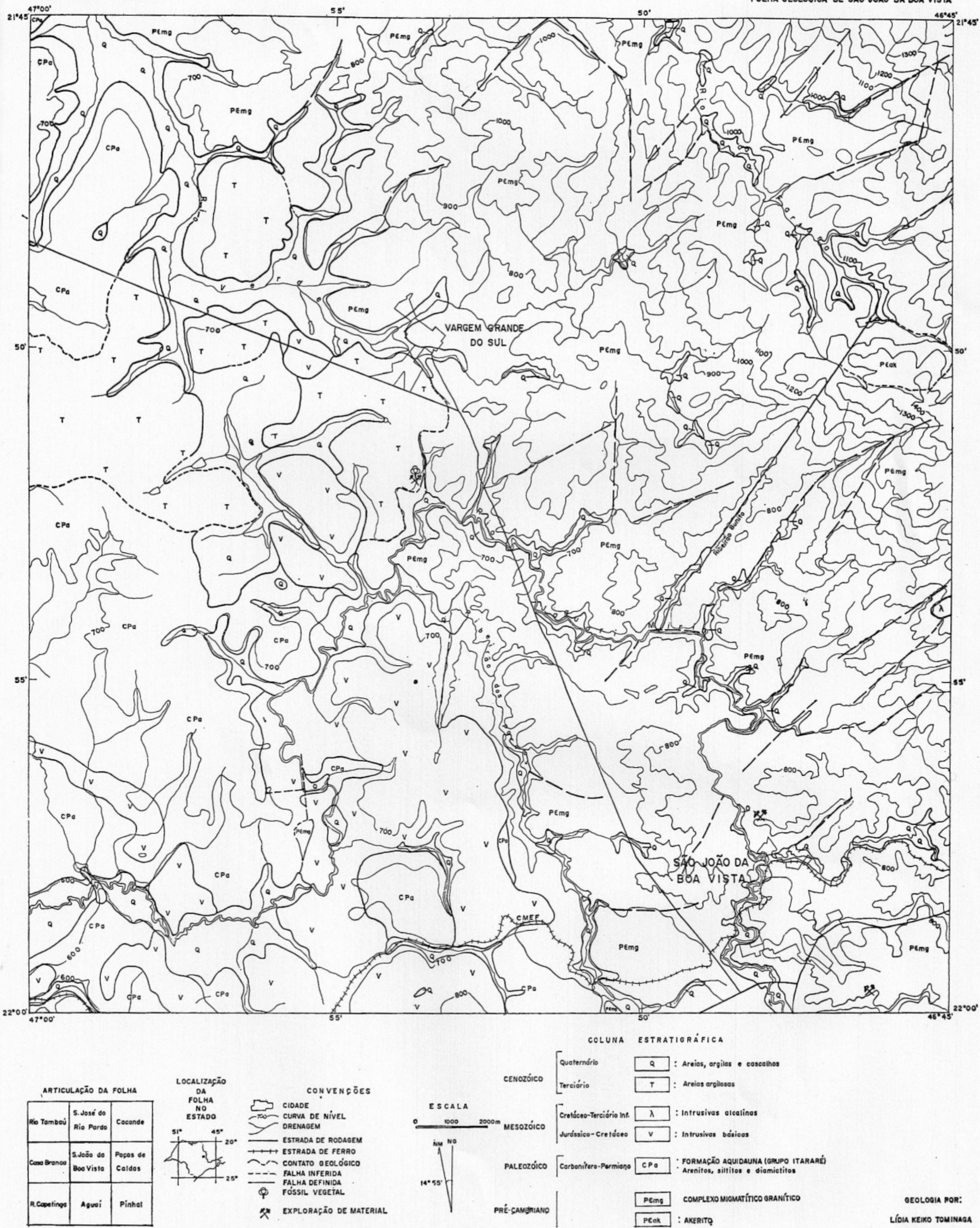


\section{BIBLIOGRAFIA}

ALMEIDA, F. F. M. de - 1964 - Fundamentos geológicos do relevo paulista. In: São Paulo. Instituto Geográfico e Geológico. Geologia do Estado de São Paulo. São Paulo. p. 169-263 (Boletim n. ${ }^{\circ} 41$ ).

- - 1964 - Grupo São Bento. In: São Paulo. Instituto Geográfico e Geológico. Geologia do Estado de São Paulo. São Paulo. p. 85-100 (Boletim n. ${ }^{\circ} 41$ ).

AMARAL, G. et alii - 1966 - PotassiumArgon dates of basaltics rocks from Southern Brazil. Geochim. Cosmochim. Acta. Oxford, 30:159-189.

COMPANHIA DE PESQUISA DE RECURSOS MINERAIS - 1977 - Projeto Sapucaí; relatório final - Geologia. São Paulo, v. 1, 615 p. il.

SÃO PAULO. DEPARTAMENTO DE ÁGUAS E ENERGIA ELETRICA - 1972 - Estudo de águas subterrâneas: avaliação preliminar. São Paulo, 337p. il.

. _ - 1974 - Estudos de águas subterrâneas: região administrativa 6 , Ribeirão Preto. São Paulo, v. 1, 75p., resumo.

FUNDAÇÃO INSTITUTO BRASILEIRO DE GEOGRAFIA E ESTATISTICA. Diretoria Técnica - 1977 - Geografia do Brasil: região sudeste. Rio de Janeiro, v. 3, 667p. il.

LAHEE, F. H. - 1958 - Geologia practica. Barcelona, Omega, 874p. il.
LOCZY, L. de \& LADEIRA, E. A. - 1976 Geologia estrutural e introdução à geotectônica. São Paulo, Blücher, 528p. il.

MEZZALIRA, S. - 1966 - Os fósseis do Estado de São Paulo. São Paulo, Instituto Geográfico e Geológico, 132p. il. (Boletim n. ${ }^{\circ} 45$ )

SOARES, P. C. et alii - 1973 - Geologia do Nordeste do Estado de São Paulo. In: CONGRESSO BRASILEIRO DE GEOLOGIA, 27, Aracaju, 1973. Anais. Aracaju, Sociedade Brasileira de Geologia. v. 1, p. 209-228.

SOARES, P. C. \& LANDIM, P. M. B. - 1973 - Aspectos regionais da estratigrafia da Bacia do Paraná no seu flanco nordeste. In: CONGRESSO BRASILEIRO DE GEOLOGIA, 27, Aracaju, 1973. Anais. Aracaju, Sociedade Brasileira de Geologia. v. 1, p. 243-256.

SOARES, P. C. \& LANDIM, P. M. B. - 1974 - Elementos estruturais da parte nordeste da Bacia do Paraná: classificação e gênese. In: CONGRESSO BRASILEIRO DE GEOLOGIA, 28, Porto Alegre, 1974. Anais: Porto Alegre, Sociedade Brasileira de Geologia, v. 4, p. 107-121.

SUGUIO, K. - 1973 - Introdução à Sedimentologia. São Paulo, Blücher, 528p. il.

VIEIRA, A. V. - 1973 - Geologia do centro e nordeste do Paraná e centro-sul de São Paulo. In: CONGRESSO BRASILEIRO DE GEOLOGIA, 27 Aracaju, 1973. Anais. Aracaju, Sociedade Brasileira de Geologia. v. 3, p. $259-277$. 